Revista Verde de Agroecologia e Desenvolvimento Sustentável

http://www.gvaa.com.br/revista/index.php/RVADS

ARTIGO CIENTÍFICO

DOI: http://dx.doi.org/10.18378/rvads.v10i3.3367

\title{
Estudo da cinética de secagem em camada delgada da bráctea da macambira
}

\section{Mathematical modeling and effective diffusivity of drying process of bract of macambira}

\author{
Thayze R. B. Pessoa ${ }^{1 *}$, Julianne V. F. Portela ${ }^{2}$, Ânoar A. El-Aouar ${ }^{3}$; Pierre Corrêa Martins ${ }^{3}$
}

Resumo: A macambira é uma bromélia do sertão brasileiro e a sua principal utilização para consumo de suas brácteas é na forma de produtos secos, tais como a farinha. O objetivo deste trabalho foi estudar o processo de secagem em camada delgada da bráctea da macambira (Bromelia laciniosa, Mart.) in natura a diferentes temperaturas. A secagem convectiva foi realizada a 43, 49 e $56^{\circ} \mathrm{C}$ em condições constantes de velocidade e umidade absoluta do ar. Foi utilizado um secador de leito fixo com escoamento de ar perpendicular as partículas, cujos ensaios de secagem foram conduzidos até que as amostras alcançassem massa constante. A cinética de secagem foi avaliada através das curvas experimentais de secagem. A difusividade efetiva média de umidade foi determinada através de correlações empíricas e da solução do modelo de Fick para a difusão de água líquida. $\mathrm{O}$ aumento da temperatura do ar de secagem provocou o aumento da taxa de secagem e a diminuição do conteúdo de umidade das amostras ao longo de toda operação. As correlações empíricas (análoga a lei de resfriamento de Newton e de Page) apresentaram melhores ajustes aos resultados experimentais em relação ao modelo de Fick. Os valores da difusividade média de umidade encontradas para a bráctea de macambira a 43,49 e $56^{\circ} \mathrm{C}$ foi na ordem de $10-10 \mathrm{~m} / \mathrm{s}^{2}$. Os melhores resultados para a secagem de bráctea de macambira foi a $56^{\circ} \mathrm{C}$.

Palavras-chaves: vegetais regionais, processamento, difusividade efetiva de umidade

Abstract: The macambira is a bromeliad in the Brazilian arid regions and its main use for consumption of its bract is in the form of dry products such as flour. The objective of this work was to study the drying process thin layer bract macambira (Bromeliad laciniosa Mart.) at different temperatures. The convective drying was performed at 43,49 and $56{ }^{\circ} \mathrm{C}$ under constant air conditions of speed and absolute humidity. Experimental tests were conducted in a fixed-bed dryer with air flowing perpendicular to the sample the particles to obtain constant weight. Drying kinetics was evaluated using the experimental curves drying. The average effective moisture diffusivity was determined by empirical correlations and Fick's model solution for the diffusion of liquid water. The increase in drying air temperature caused an increase in the drying rate and decreased moisture content of the samples throughout operation. The empirical correlations (analogous to Newton's law of cooling and Page) had best fits the experimental results than the model of Fick. The values of average moisture diffusivity found for bract macambira at 43,49 and $56^{\circ} \mathrm{C}$ was in the order of $10^{-10} \mathrm{~m}^{2} / \mathrm{s}$. The best results for drying bract macambira was at $56{ }^{\circ} \mathrm{C}$.

Key words: regional vegetables, processing, moisture effective diffusivity

\footnotetext{
*Autor para correspondência

Recebido para publicação em 14/04/2015; aprovado em 01/06/2015

${ }^{1}$ Doutoranda em Engenharia de Processos; Técnica em Química; Departamento de Engenharia de Alimentos; Universidade Federal da Paraíba, Cidade Universitária, Campus Universitário I, CEP: 58051-900, João Pessoa, Paraíba (PB), Brasil, Telefone: (83) 3216-7357, e-mail: thayzepessoa1 @ yahoo.com.br

${ }^{2}$ Professora do Curso Bacharelado em Nutrição; Campus Senador Helvídio Nunes de Barros; Universidade Federal do Piauí - CSHNB/UFPI, Rua Cícero Duarte, n095, Junco, CEP: 64607-670, Picos, Piauí (PI), Brasil; Telefone: (89) 3422 - 1018, e-mail: julianneportela@ufpi.edu.br

${ }^{3}$ Professores do Curso Bacharelado em Engenharia de Alimentos ; Departamento de Engenharia de Alimentos; Universidade Federal da Paraíba, Cidade Universitária, Campus Universitário I, CEP: 58051-900, João Pessoa, Paraíba (PB), Brasil, Telefone: (83) 3216-7357, e-mail: anoarabbas@ gmail.com; pierre@ct.ufpb.br
} 


\section{INTRODUÇÃO}

O nordeste brasileiro é constituído, em sua maior parte, por regiões de baixa pluviometria, favorecendo o desenvolvimento de plantas xerófilas, destacando-se, entre elas, a macambira (Bromelia laciniosa Mart.), da família bromeliaceae (BARBOSA, 2003).

A macambira é encontrada na caatinga dos sertões do nordeste, desde a Bahia ao Piauí. Na Paraíba foi detectada a presença de cerca de 100 plantas das espécies Encholirion spectabile Mart. e Bromelia laciniosa Mart. (GONÇALVES, 1997; LIMA, 1996). A macambira (Bromelia laciniosa Mart.) é uma planta herbácea, acaule, folhas linear lanceoladas, dispostas em roseta densa, com as margens eriçadas de espinhos fortes, inflorescência axilar, fruto cápsula tricarpelar (CAVALCANTI et al., 2000). Como é uma planta epífita consegue apresentar a capacidade de crescimento em lugares de difícil acesso, extraindo nutrientes essenciais para uma excelente composição mesmo de solo rochoso. No passado, ela foi o símbolo de sobrevivência para o povo nordestino, preservando a sobrevivência de milhares de peregrinos da seca. É utilizada na alimentação na forma de farinha, acompanhando a carne e o leite (PORTELA et al., 2014).

A massa comestível é extraída da base das folhas (brácteas). Apresenta cor branca amarelada, de cheiro característico. A bráctea apresenta conteúdos significativos de proteínas, carboidratos, amidos, fibras, minerais e umidade para a dieta alimentar de seus consumidores, sendo utilizado para formulação de produtos alimentícios acabados ou intermediários, tais como a farinha (LIMA, 2001; VAINSENCHER, 2010). No entanto, a macambira pode retornar a alimentação humana através do estudo de parâmetros de operação para o seu processamento e produção de diversos produtos alimentícios, pois sua farinha apresenta alto teor de cálcio, boa digestibilidade e nenhuma toxidez (BESSA, 1982).

A secagem de alimentos é uma operação na qual se transfere calor ao material para a retirada do seu conteúdo de umidade até se obter condições de inibição do crescimento microbiano e a deterioração física e química do mesmo. Trata-se de um processo com transporte simultâneo de calor e massa, acompanhado de mudança de fase. Geralmente o material seco apresenta conteúdo de umidade inferior a $9 \%$ em peso de água e é denominado de produto desidratado (BARBANTI et al., 1994; LEWICKI; JAKUBCZYK, 2004). O coeficiente de difusão mássica da umidade através da matriz sólida do material é uma difusividade efetiva de umidade que é o parâmetro de transporte de massa que representa a facilidade de migração, de retirada de umidade do seu interior. Ele pode ser obtido através da analogia dos resultados experimentais de secagem com a solução da equação de difusão líquida de Fick (MARTINAZZO et al., 2007). A difusividade efetiva de umidade varia com as condições de secagem aplicadas ao material (geometria, tamanho) e ao ar (umidade, velocidade, temperatura) e é utilizada para avaliar, comparar o desempenho da operação a diferentes temperaturas (OLIVEIRA et al., 2006).

A literatura apresenta escassas informações sobre a secagem de macambira (Bromelia laciniosa Mart.) e principalmente de sua bráctea. Isto sugere estudos sobre os parâmetros de operação de secagem das partes desta bromélia aproveitáveis para o consumo humano. O presente trabalho tem como objetivo estudar a secagem de bráctea de macambira (Bromelia laciniosa, Mart.) a diferentes temperatura para fornecer informações ao desenvolvimento de linhas de produção de farinha de macambira.

\section{MATERIAL E MÉTODOS}

A matéria-prima utilizada foram as brácteas de macambira (Bromelia laciniosa Mart.) adquiridas em uma propriedade rural do município de Soledade-PB.

Os ensaios experimentais foram realizados no Laboratório de Engenharia de Alimentos (LEA) da Universidade Federal da Paraíba. Os equipamentos utilizados foram um secador convectivo de bandejas com escoamento de ar perpendicular as amostras com um sistema de controle de temperatura e de velocidade da corrente gasosa desenvolvido no LEA, anemômetro de fio quente (modelo velocicheck, marca TSI Incorporated, EUA), termohigrômetro (modelo digital Hygro-Thermometer, France), balanças analíticas, estufa (marca Marconi, modelo MA 030/12, Brasil), facas de aço inox e demais vidrarias de laboratório.

As raízes das bromélias foram manipuladas no LEA obtendose as brácteas de macambira. Essas foram submetidas ao corte manual na forma de lâminas retangulares (geometria de placa plana infinita), cuja espessura do material foi de 2,2 $\pm 0,15$ $\mathrm{mm}$. Em seguida foi realizada a retirada manual da película externa da bráctea, denominada epiderme. As partículas apresentaram-se como finas e estreitas lâminas. Os ensaios de secagem foram realizados a $43{ }^{\circ} \mathrm{C}, 49{ }^{\circ} \mathrm{C}$ e $56{ }^{\circ} \mathrm{C}$ em duplicata. Foram obtidas curvas de secagem através de sucessivas pesagens da massa do material no decorrer da operação sob condições constante de velocidade $(1,0 \mathrm{~m} / \mathrm{s})$ e de temperatura do ar. As amostras foram pesadas a cada 15 minutos até a segunda (02) hora de secagem e a cada 30 minutos até massa constante das amostras.

A determinação de massa de sólido seca das amostras foi realizada em estufa a $105{ }^{\circ} \mathrm{C}$ até massa constante e em duplicata.

A cinética de secagem foi estudada através das curvas do conteúdo de umidade, em base seca (X), em relação ao tempo de secagem $(\mathrm{t})$ e da taxa de secagem $(\mathrm{N})$ em relação ao conteúdo de umidade $(\mathrm{X})$ das amostras.

A difusividade efetiva média de umidade foi obtida através das curvas experimentais do adimensional de umidade $\left(\frac{\bar{X}-X_{e}}{X_{0}-X_{e}}\right)$ em relação ao tempo de secagem. A umidade de equilíbrio das amostras secas $\left(\mathrm{X}_{\mathrm{e}}\right)$ foi considerada igual a umidade final do material em seus respectivos ensaios de secagem, conforme El-Aouar e Murr (2003). Foram utilizadas correlações empíricas e a equação de Fick para a difusão de água líquida, apresentadas a seguir, para a determinação da difusividade efetiva média de umidade.

A Equação 1 é a solução do modelo de Fick obtida por Crank (1975) para a migração de umidade de uma placa plana infinita, migração por ambos os lados, sem resistência externa na superfície e tempos longos de secagem. 
$\left(\frac{\bar{X}-\mathrm{X}_{\mathrm{e}}}{\mathrm{X}-\mathrm{X}_{\mathrm{e}}}\right)=\left(\frac{8}{\pi^{2}}\right) \exp \left(-\frac{\pi^{2} \mathrm{D}_{\mathrm{ef}} \mathrm{t}}{\left(2 \mathrm{~L}_{\mathrm{e}}\right)^{2}}\right) \therefore \mathrm{L}_{\mathrm{e}}=\frac{\mathrm{L}_{\text {amostra }}}{2}$

onde: $\mathrm{D}_{\mathrm{ef}}=$ Difusividade efetiva $\left(\mathrm{m}^{2} / \mathrm{s}\right) ; \overline{\mathrm{X}}=$ conteúdo médio de umidade $\left(\mathrm{kg}_{\text {água }} / \mathrm{kg}_{\text {sól. seco }}\right) ; \mathrm{X}_{\mathrm{e}}=$ conteúdo de umidade de equilíbrio ( $\left.\mathrm{kg}_{\text {água }} / \mathrm{kg}_{\text {sól. seco }}\right) ; \mathrm{X}_{0}=$ conteúdo de umidade inicial $\left(\mathrm{kg}_{\text {água }} / \mathrm{kg}_{\text {sól. seco }}\right) ; \mathrm{t}=$ tempo $(\mathrm{s}) ; \mathrm{L}_{\mathrm{e}}=$ comprimento característico $=$ metade da espessura da amostra $(\mathrm{m}) ; \mathrm{X}_{\mathrm{e}}=$ conteúdo de umidade de equilíbrio do material $\left(\mathrm{kg}_{\text {água }} / \mathrm{kg}_{\text {sól. seco }}\right)$.

A correlação análoga a lei de resfriamento de Newton, apresentada pela Equação 2, é utilizada para a determinação da difusividade efetiva média de umidade na secagem de materiais com alto conteúdo de umidade.

$$
\frac{\bar{X}-X_{e}}{X_{0}-X_{e}}=A \cdot \exp (K t)
$$

onde: $\mathrm{t}=$ tempo de secagem; $\mathrm{K}=$ constante de ajuste, denominada de constante de secagem; $\mathrm{A}=$ constante $\mathrm{de}$ ajuste.

A Equação 3 é a correlação de Page (1949) para caracterizar a migração de água livre na secagem de sólidos granulares, ajustada a dois termos exponenciais.

$$
\frac{\bar{X}-X_{e}}{X_{0}-X_{e}}=A \exp \left(K \cdot t^{N}\right)
$$

onde: $\mathrm{t}=$ tempo de secagem; $\mathrm{K}=$ constante de ajuste, denominada de constante de secagem; $\mathrm{B}=$ constante de ajuste.

As correlações empíricas apresentadas nas Equações 2 e 3 são análogas a solução numérica da equação analítica da lei de Fick proposta por Cranck (1975) para tempos longos de secagem (Eq. 1). Assim, a difusividade efetiva média de umidade para secagem pelos dois lados do material pode ser determinada pela analogia das expressões 1 e 2, resultando na Equação 4 (MARTINS; PINTO, 2003).

$$
\overline{\mathrm{D}}_{\mathrm{ef}}=\frac{\mathrm{L}_{\mathrm{m}}^{2} \mathrm{~K}}{\pi^{2}}
$$

onde: $\overline{\mathrm{D}}_{\mathrm{ef}}$ é a difusividade efetiva média de umidade, $\mathrm{L}_{\mathrm{m}}$ é a espessura média das amostras $\left(\mathrm{L}_{\mathrm{m}}=\left(\frac{\mathrm{L}_{\text {final }}-\mathrm{L}_{\text {inicial }}}{2}\right)\right)$, K é o parâmetro de ajuste experimental obtido nas Equações 2 e 3 denominado de constante de secagem e $\pi=3,14$.

Para o ajuste dos modelos matemáticos aos dados experimentais de secagem, realizou-se a análise de regressão não-linear por meio do programa computacional. A escolha do melhor ajuste dos modelos aos dados experimentais foi realizada pelo cálculo do coeficiente de determinação $\left(\mathrm{R}^{2}\right)$, entre as respostas observadas e os valores previstos pelo modelo ajustado (LOMAURO et al., 1985).

\section{RESULTADOS E DISCUSSÃO}

A Tabela 1 apresenta os resultados das determinações dos conteúdos de umidade e de sólidos totais da bráctea de macambira utilizada nos ensaios de secagem a diferentes temperaturas.

Tabela 1 - Conteúdos de sólidos totais e de umidade da bráctea de macambira in natura

\begin{tabular}{cc}
\hline Determinações & Bráctea de macambira $^{\mathrm{i}}$ \\
\hline Sólidos totais $(\%)$ & $15,72 \pm 1,85$ \\
Conteúdo de umidade x, b.u $(\%)$ & $84,28 \pm 1,85$ \\
\hline
\end{tabular}

Média de três determinações

O conteúdo de umidade da bráctea de macambira in natura apresentado na Tabela 1 está de acordo com os resultados de Portela et al. (2014). Portanto, ela pode ser considerada como um vegetal de alto conteúdo de umidade para o processo de secagem. No entanto, a bráctea de macambira é formada por carboidratos complexos (amido) e de fibras, diferenciando-a das polpas de frutos e de outras hortaliças, tal como a cebola, com alto teor de umidade.

Os resultados da secagem da bráctea de macambira a diferentes temperaturas estão inicialmente apresentados através das curvas do conteúdo de umidade em relação ao tempo de secagem apresentadas na Figura 1.

Figura 1 - Curvas do conteúdo umidade (X) em relação ao tempo de secagem da bráctea de macambira expressando o conteúdo de umidade em: (A) valores absolutos; (B) valores adimensionais

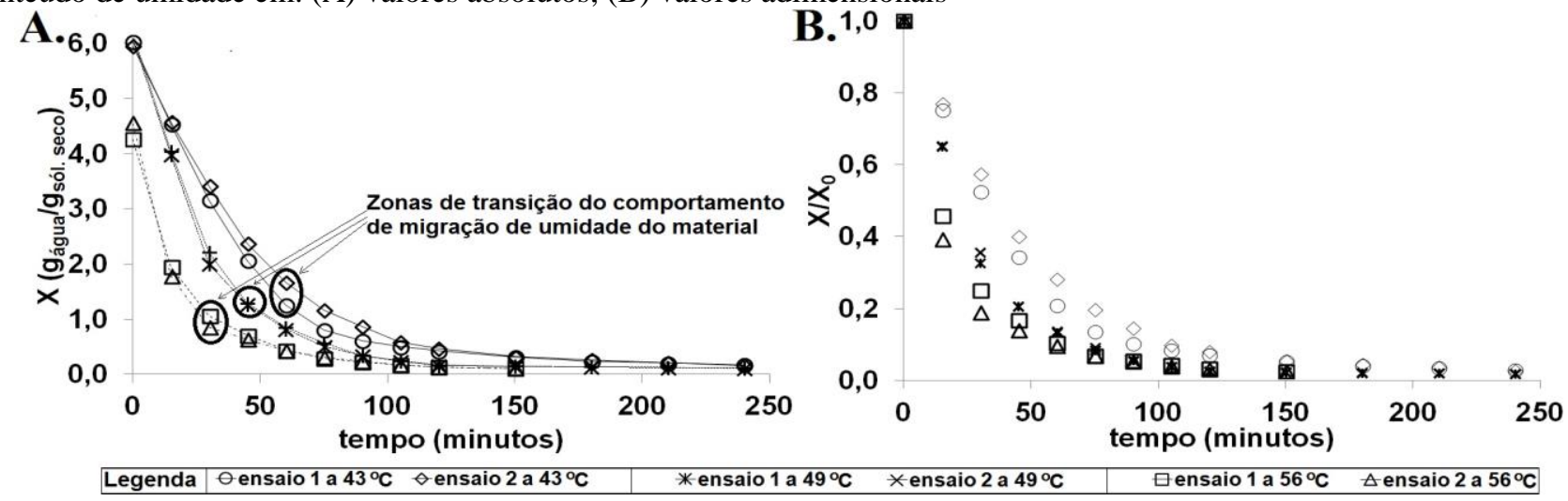


Observa-se na Figura 1A que a declividade das curvas acentua-se com o aumento da temperatura dos ensaios de secagem. As amostras de bráctea macambira submetidas aos ensaios de secagem a $43{ }^{\circ} \mathrm{C}$ e $49{ }^{\circ} \mathrm{C}$ apresentaram conteúdo de umidade inicial similar $\left(\mathrm{X}_{0}=6,0 \mathrm{~g}_{\text {água }} / \mathrm{g}_{\text {sólido seco }}\right)$ enquanto as amostras secas a $56{ }^{0} \mathrm{C}$ exibiram um menor conteúdo de umidade inicial $\left(\mathrm{X}_{0}=4,5 \mathrm{~g}_{\text {água }} / \mathrm{g}_{\text {sólido seco }}\right)$. No entanto, tal diferença não influenciou no comportamento de migração de umidade do material no decorrer da operação, pois se verifica a distinta separação entre as curvas da Figura 1A para o período de 50 minutos de secagem. Nesse intervalo, o aumento da temperatura de secagem proporciona uma maior perda de umidade das amostras demonstrada pela sobreposição gradativa das curvas dos ensaios a $49{ }^{\circ} \mathrm{C}$ e $43{ }^{\circ} \mathrm{C}$ sobre os resultados obtidos a $56{ }^{\circ} \mathrm{C}$. Nas regiões circuladas das curvas da Figura $1 \mathrm{~A}$ verifica-se a mudança do comportamento do mecanismo de migração de umidade do material para a corrente de ar. Essas zonas de transição de umidade representam a distinção das duas etapas do período de taxa de secagem decrescente. Observa-se novamente que o aumento da temperatura do ar de secagem proporciona uma gradativa diminuição dos valores de umidade e tempo para essas zonas de transição.

Na Figura 1B estão traçadas as curvas dos adimensionais de umidade em relação ao tempo de secagem para descartar a interferência da diferença entre e conteúdo de umidade das amostras submetidas aos seus respectivos ensaios de secagem. Observa-se que o comportamento das curvas não se alterou, porém as curvas dos ensaios a $49{ }^{0} \mathrm{C}$ e $56{ }^{0} \mathrm{C}$ têm maior aproximação a partir do período de 50 min. No entanto, o material seco apresentou uma gradativa diminuição do seu conteúdo de umidade final com o aumento da temperatura de secagem, conforme os resultados apresentados na Tabela 2 .
Tabela 2 - Conteúdo de umidade final para secagem em camada delgada da bráctea de macambira a diferentes temperaturas

\begin{tabular}{ccc}
\hline $\begin{array}{c}\text { Temperatura } \\
\left({ }^{0} \mathrm{C}\right)\end{array}$ & $\begin{array}{c}\text { Conteúdo de umidade } \\
\text { final, } \mathrm{x}(\mathrm{b} . \mathrm{u} ., \%)^{\mathbf{i}}\end{array}$ & $\begin{array}{c}\text { Tempo final } \\
(\mathrm{min})\end{array}$ \\
\hline 43 & $14,27 \pm 0,48$ & 240 \\
49 & $10,65 \pm 0,031$ & 240 \\
56 & $9,13 \pm 0,04$ & 170 \\
\hline
\end{tabular}

${ }^{\mathrm{i}}$ Média de dois ensaios

Segundo as informações da Tabela 2, o conteúdo de umidade encontrado nas brácteas de macambira secas nas três temperaturas utilizadas encontra-se de acordo com o padrão estabelecido pela ANVISA (1978) que exige um conteúdo máximo de $15 \%$ em peso de umidade, em base úmida, para as farinhas comerciais. A secagem a $43{ }^{\circ} \mathrm{C}$ não seria indicada para a obtenção da farinha da bráctea da macambira, pois as outras etapas de produção da farinha (moagem e peneiramento) geralmente elevam o conteúdo de umidade do material seco. Assim, o produto seco não deve apresentar um conteúdo de umidade próximo ao máximo permitido (15\%) pela legislação para as farinhas comerciais. Verifica-se que as temperaturas do ar de secagem de $56^{\circ} \mathrm{C}$ e $49^{\circ} \mathrm{C}$ são as mais adequadas para a produção de farinha comercial de bráctea de macambira. A bráctea de macambira seca a $56{ }^{\circ} \mathrm{C}$ atingiu sua umidade de equilíbrio em um menor tempo de secagem (170 min) em relação aos ensaios realizados a $43^{\circ} \mathrm{C}$ e $49^{\circ} \mathrm{C}(240$ $\mathrm{min}$ ), de acordo com os resultados encontrados por Portela et al. (2014) na secagem de miolo de macambira em camada delgada para as mesmas temperaturas.

A caracterização da cinética de secagem da bráctea de macambira é melhor averiguada através das curvas da taxa de secagem $(\mathrm{N})$ em relação ao conteúdo de umidade $(\mathrm{X})$ das amostras apresentadas na Figura 2A. A Figura 2B apresenta o comportamento dessas curvas para o final da segunda etapa da taxa decrescente de secagem.

Figura 2 - Curvas da taxa de secagem $(\mathrm{N})$ em relação ao conteúdo de umidade para a bráctea de macambira, sendo: (A) resultados gerais; (B) resultados da segunda etapa do período de taxa decrescente de secagem

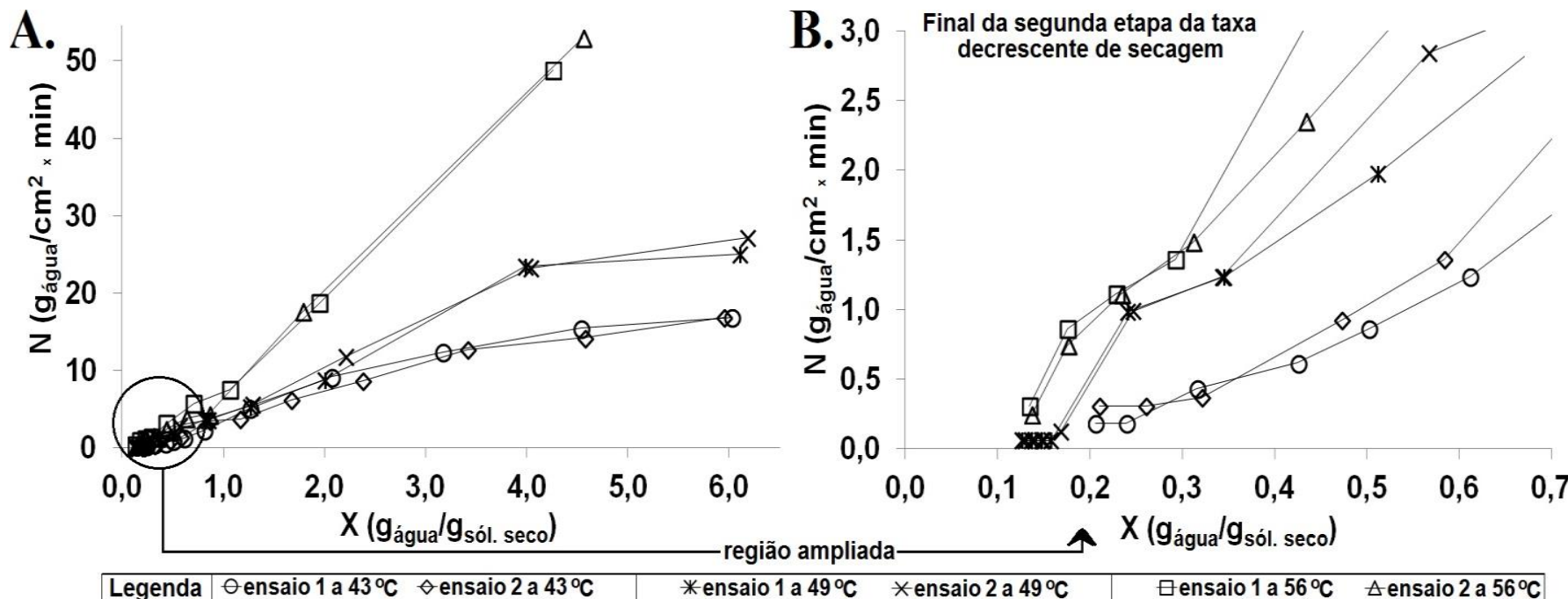

Pode-se observar na Figura 2 que o comportamento da taxa de secagem em relação ao conteúdo de umidade do material é decrescente ao longo de todo processo de secagem. Provavelmente deve ocorrer um pequeno período de taxa de evaporação superficial de umidade pelo fato do alto conteúdo de umidade inicial do material. A amplitude de tempo utilizada para as pesagens do material durante os momentos iniciais de secagem não conseguiu identificar este 
comportamento que caracteriza o período de taxa constante de secagem. No entanto, a secagem da bráctea de macambira ocorreu predominante no período de taxa decrescente de secagem de acordo com as informações de diversas pesquisas similares a esse estudo (GOUVEIA et al., 2003; PORTELA et al., 2014). Esses trabalhos relatam que este comportamento de ausência ou breve período da taxa constante de secagem é característico de produtos que apresentam prioritariamente na sua composição, constituintes com elevada afinidade por moléculas de água. A secagem em camada delgada com escoamento de ar perpendicular a uma partícula fina e estreita é outro fator que resulta nesse comportamento decrescente das curvas de secagem ao longo da operação, segundo Martins et al. (2002). Tais pesquisadores compararam o comportamento da secagem em camada delgada de partículas de cebola com escoamentos paralelo e perpendicular ao leito de sólidos a $60{ }^{0} \mathrm{C}$. Observaram que o período de taxa constante teve comportamento linear para o material seco com escoamento paralelo as partículas e decrescente para o escoamento perpendicular ao material. Portanto, as informações obtidas nas curvas da Figura 2 estão relacionadas a temperatura dos ensaios de secagem. Verifica-se na Figura 2A que a crescente sobreposição das curvas da taxa de secagem ocorrem de acordo com o aumento da temperatura dos ensaios de secagem. A Figura 2B apresenta a ampliação do traçado das curvas da taxa de secagem para a etapa final do período de taxa decrescente de secagem, na qual se pode observar o mesmo comportamento de sobreposição das curvas. Portanto, a taxa de secagem eleva-se com o aumento da temperatura ao longo de todo processo de secagem em camada delgada de bráctea de macambira a $60{ }^{\circ} \mathrm{C}$.

A difusividade efetiva média de umidade da bráctea de macambira foi determinada através de curvas experimentais do adimensional de água livre $\left(\mathrm{X}-\mathrm{X}_{0} / \mathrm{Xe}-\mathrm{X}_{0}\right)$ em função do tempo dos ensaios de secagem a diferentes temperaturas apresentadas na Figura 3.
Figura 3 - Curvas do adimensional de água livre em relação ao tempo de secagem para a bráctea de macambira seca a diferentes temperaturas

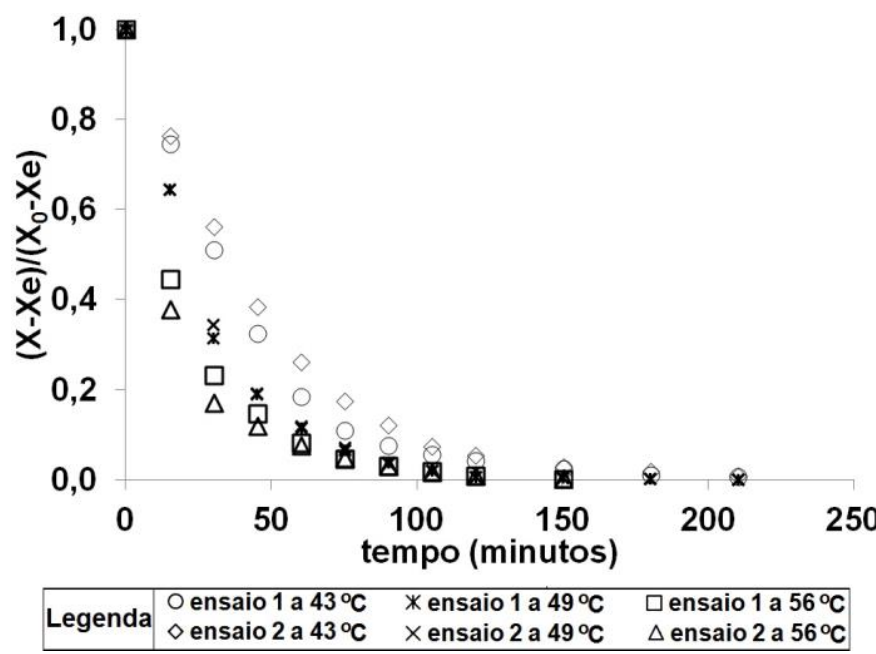

As curvas do adimensional de água livre em relação ao tempo da Figura 3 apresentam comportamento similar ao demonstrada pelas curvas do adimensional de umidade em relação ao tempo (Fig. 1B). As curvas apresentam comportamento exponencial decrescente e a sua sobreposição crescente ocorre com a diminuição da temperatura do ar dos ensaios de secagem. A espessura média das partículas apresentou um valor similar para todos ensaios de secagem igual a $0,18 \pm 0,01 \mathrm{~cm}$. A correlação similar a lei de resfriamento de Newton, denominada empírica, a correlação de Page e a solução analítica do modelo de Fick para a difusão de água líquida foram ajustadas através das curvas experimentais apresentadas na Figura 3, cujos valores obtidos para a difusividade efetiva média de umidade e o coeficiente de correlação estão apresentados na Tabela 3.

Tabela 3 - Difusividade efetiva média de umidade $\left(\right.$ Def $\left._{\text {média }}\right)$ para secagem em camada delgada da bráctea de macambira a $60{ }^{\circ} \mathrm{C}$

\begin{tabular}{cccccccc}
\hline \begin{tabular}{c} 
Temperatura do $\begin{array}{c}\text { Resultados das equações de ajuste dos dados experimentais } \\
\text { ensaio de } \\
\text { secagem }\left({ }^{0} \mathrm{C}\right)\end{array}$ \\
\cline { 2 - 7 }
\end{tabular} & $\begin{array}{c}\text { Correlação Empírica } \\
\mathrm{R}^{2}(\%)\end{array}$ & $\begin{array}{c}\text { Correlação de Page } \\
\operatorname{Def}_{\text {média }}\left(\mathrm{m}^{2} / \mathrm{s}\right)\end{array}$ & $\mathrm{R}^{2}(\%)$ & $\operatorname{Def}_{\text {média }}\left(\mathrm{m}^{2} / \mathrm{s}\right)$ & \multicolumn{2}{c}{$\mathrm{Modelo} \mathrm{de} \mathrm{Fick}^{2}(\%)$} & $\mathrm{Def}_{\text {média }}\left(\mathrm{m}^{2} / \mathrm{s}\right)$ \\
\hline 43 & $99,8 \pm 0,1$ & $1,610^{-10} \pm 3,510^{-11}$ & $99,9 \pm 0,1$ & $6,110^{-11} \pm 1,010^{-12}$ & $99,1 \pm 0,2$ & $1,210^{-10} \pm 6,010^{-12}$ \\
49 & $99,8 \pm 0,1$ & $1,910^{-10} \pm 2,710^{-12}$ & $99,9 \pm 0,1$ & $1,210^{-10} \pm 2,910^{-13}$ & $96,9 \pm 0,1$ & $1,910^{-10} \pm 7,510^{-13}$ \\
56 & $99,6 \pm 0,1$ & $2,910^{-10} \pm 2,610^{-11}$ & $99,9 \pm 0,1$ & $6,310^{-10} \pm 1,510^{-10}$ & $97,4 \pm 0,4$ & $2,110^{-10} \pm 3,510^{-13}$ \\
\hline
\end{tabular}

Média de dois ensaios

Os valores da difusividade efetiva média de umidade da bráctea de macambira apresentadas na Tabela 3 aumentam com o aumento da temperatura para as equações de ajustes utilizadas. Esse comportamento está de acordo com os resultados apresentados pelas curvas da taxa de secagem (Fig. 2), cujos valores aumentam com o incremento de temperatura dos ensaios. As correlações de Page e empírica apresentam altos valores de coeficiente de correlação $\left(\mathrm{R}^{2}\right.$ acima de $99,0 \%)$ nas diferentes temperaturas de secagem. A correlação de Page apresenta melhor desempenho de ajuste em relação às demais em todos os ensaios. Assim, pode-se utilizar as correlações empírica e de Page para determinar a Def média $_{\text {da }}$ bráctea de macambira nas temperaturas estudadas. A bráctea de macambira apresenta um comportamento diferente de migração de umidade em relação aos alimentos fibrosos com alto conteúdo de umidade. Nesses materiais, a correlação empírica apresenta correlações de ajustes consideravelmente superiores a correlação de Page para a determinação Def média. O modelo de Fick apresenta menor desempenho de ajuste em relação as demais, expressando valores de correlação

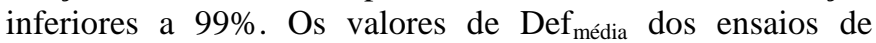
secagem obtidos pelas equações de ajuste se encontram na 
mesma ordem de grandeza $\left(10^{-10} \mathrm{~m}^{2} / \mathrm{s}\right)$, caracterizando a difusão de água líquida e de acordo com as informações da literatura para este tipo de material e condições de operação (MARTINS et al., 2004; SILVA et al., 2009).
A averiguação de ajuste das correlações empírica e de Page e do modelo de Fick em relação aos dados experimentais está expressa através das curvas traçadas do adimensional de água livre em relação ao tempo de secagem apresentadas na Figura 4.

Figura 4 - Curvas traçadas a partir das equações de ajuste e dados experimentais do adimensional de água livre em relação ao tempo de secagem para a bráctea de macambira seca a diferentes temperaturas, sendo: (A) ensaio a $43{ }^{0} \mathrm{C}$; (B) ensaio a $49{ }^{\circ} \mathrm{C}$; (C) ensaio a $56{ }^{\circ} \mathrm{C}$

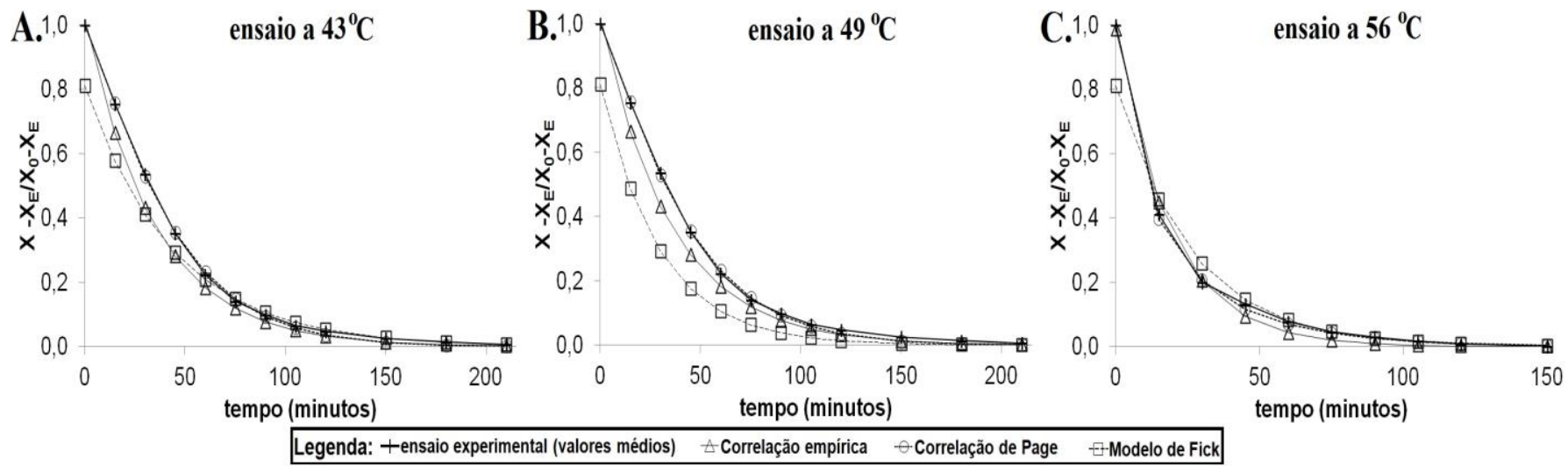

As curvas apresentadas na Figura 4 confirmam os resultados apresentados na Tabela 3 demonstrando que as correlações Empírica e de Page se ajustam melhor aos dados experimentais em relação ao modelo de Fick. Este fato está evidenciado na Figura 4B, a qual apresenta as sobreposições das curvas de ajuste das correlações e do modelo de Fick em relação aos resultados experimentais. $O$ traçado da curva de ajuste da correlação de Page está combinado com a curva dos resultados experimentais. A curva de ajuste da correlação empírica antecede brevemente a curva com os resultados experimentais enquanto a curva de ajuste do modelo de Fick está completamente deslocada dos mesmos. Pode-se perceber nas Figuras 4A e 4C que os traçados das curvas de ajuste das correlações estão mais justapostos aos dados experimentais do que a curva de ajuste do modelo de Fick.

\section{CONCLUSÕES}

Os ensaios de secagem a diferentes temperaturas produziram um material seco com umidade final inferior ao limite máximo de umidade para farinhas comerciais exigido pela legislação brasileira.

$\mathrm{O}$ aumento da temperatura de secagem diminui o conteúdo de umidade final do produto e aumenta a taxa de secagem ao longo do processo.

A difusividade efetiva média de umidade aumenta com o aumento da temperatura e apresenta valores na ordem $10^{-10} \mathrm{~m}^{2} / \mathrm{s}$ para a bráctea de macambira.

As correlações de Page e Empírica, análoga a lei de Newton para o resfriamento, apresentam melhor ajuste aos resultados experimentais para a determinação da difusividade efetiva média de umidade em relação ao modelo de Fick.

Os ensaios de secagem a $56{ }^{0} \mathrm{C}$ apresentaram os melhores resultados de secagem para a bráctea de macambira.

\section{REFERÊNCIAS BIBLIOGRÁFICAS}

AGÊNCIA NACIONAL DE VIGILÂNCIA SANITÁRIA ANVISA. Resolução CNNPA n. 12 de 1978. Diário Oficial da União, Brasília, 24 de Julho de 1978. Disponível em: <http://www.anvisa.gov.br>. Acesso em: 16 de Fevereiro de 2010.

BARBANTI, D.; MASTROCOLA, D.; SEVERINI, C. Air drying of plums. A comparison among twelve cultivars. Sciences des Aliments, n. 14, p. 61-73, 1994.

BARBOSA, H. P.; BARBOSA, C. U, G. Avaliação de Nutrientes, na Raiz e Parte Aérea, de Plantas do SemiÁrido Paraibano. Revista de Ciências da Saúde Nova Esperança, João Pessoa, v. 1, n. 1, p. 121-128, 2003.

BESSA, M. N. A macambira (Bromelia forrageira), 2 edição, Natal: EMPARN/ Coleção Mossoroense, 1982. $135 \mathrm{p}$.

CAVALCANTI, N. B.; LIMA, J. L. S.; RESENDE, G. M.; BRITO, L. T. L.; ARAUJO, F. P. Macambira (Bromelia laciniosa Mart.): da utilização a extinção. In: REUNIÃO NORDESTINA DE BOTÂNICA, 23., 2000, Recife, PE. Programa e resumos. Recife: SBB- Seção Regional de Pernambuco; UFRPE, 2000. p. 199.

CRANK, J. The Mathematics of Diffusion, $2^{\mathrm{a}}$ ed., S.I Claredon Press Oxford, 1975.414p.

EL-AQUAR, Â. A.; MURR, F. E. X. Estudo e Modelagem da Cinética de Desidratação Osmótica do Mamão Formosa (Carica papaya L.). Ciência e Tecnologia de Alimentos, Campinas, v. 24, n. 1, jan-abr., p. 69-75, 2003.

GONÇALVES, M. M. S. A macambira nos seus aspectos ecológicos e utilitários. Monografia (Especialização em ensino de ciências) - Faculdade de Ciências e Tecnologia, 
Universidade Estadual da Paraíba, Campina Grande, PB, 1997.

GOUVEIA, J. P. G.; ALMEIDA; F. A. C., FARIAS, E. S.; SILVA, M. M., CHAVES; M. C. V., REIS, L. S. Determinação das curvas de secagem em frutos de cajá. Revista Brasileira de Produtos Agroindustriais, Campina Grande, Especial, n. 1, p. 65-68, 2003.

LEWICKI, P. P.; JACUBCZYK, E. Effect of hot air temperature on mechanical properties of dried apples. Journal of Food Engineering, v. 64, p. 307-314, 2004.

LIMA, J. L. S. Plantas forrageiras das caatingas - usos e potencialidades. Petrolina, PE: EMBRAPACPATSA/PNE/ERG-KEW, 1996. 44p.

LIMA, J. A. Obtenção e Caracterização da Farinha de Batata-Doce (Ipoemea Batatas L. CV. "cenoura") Parborizada. Disssertação (Mestrado em Ciências e Tecnologia de Alimentos) - Universidade Federal da Paraíba, João Pessoa, PB, 2001.

LOMAURO, C. J.; BAKSHI, A. S.; LABUSA, T. P. Evaluation of food moisture sorption isotherm equations. Part I: fruit, vegetable and meat products. Lebensmittel Wissenschaft and Technologies. v. 18, p. 112-122, 1985 .

MARTINAZZO, A. P.; CORRÊA, P. C.; MELO, E. C.; BARBOSA, F. F. Difusividade efetiva em folhas de Cymbopogon citratus (DC.) Stapf submetidas à secagem com diferentes comprimentos de corte e temperaturas do ar. Revista Brasileira de Plantas Medicinais, v. 9, p. 6872, 2007.

MARTINS, P. C.; PINTO, L. A. A. Caracterização da Secagem de Cebola (Allium cepa $\mathrm{L}$ ) em Camada Delgada e da Reidratação do Produto Desidratado. Brazilian Journal of Food Technology, Campinas, v. 6, n. 2, p. 143-151, jul./dez., 2003.
MARTINS, P. C.; PORTO, P. S. S.; PINTO, L. A. A. Estudo das propriedades físicas e de transporte na secagem de cebola (Allium cepa L.) em camada delgada. Ciência e Tecnologia de Alimentos, Campinas, v. 24, n. 3, jul.-set., p. 319-326, 2004.

MARTINS, P. C.; PORTO, P. S. S.; PINTO, M. L. M.; BATISTA, L. M.; MORTOLA, V. B.; VALCARENGHI, L. V.; PINTO, L. A. A. Secagem de cebola (Allium cepa L) em camada delgada: análise dos escoamentos de ar paralelo e perpendicular. In: Congresso Brasileiro de Sistemas Particulados, 2002, $30^{\circ}$ ENEMP. São Carlos: UFSCar, p. 1-6, 2002.

OLIVEIRA, R. A.; OLIVEIRA, W. P.; PARK, K. J. Determinação da difusividade efetiva de raiz de chicória. Engenharia Agrícola, v. 26, p. 181-189, 2006.

PAGE, G. E. Factors influencing the maximum of air drying shelled corn in thin layer. 1949. [Dissertação de Mestrado]. Indiana, USA: Purdue University, 1949.

PORTELA, G. V. F.; PESSOA, T. R. B.; EL-AOUAR, A. A. Modelagem matemática e difusividade efetiva do processo de secagem do miolo da macambira. Revista Verde de Agroecologia e Desenvolvimento Sustentável, Mossoró, v. 9, n. 1, p. 271-278, 2014.

SILVA, A. S.; MELO, K. S.; ALVES, N. M.; FERNANDES, T. K. S.; FARIAS, P. A. Cinética de secagem em camada fina da banana maçã em secador de leito fixo. Revista Brasileira de Produtos Agroindustriais, Campina Grande, vol. 11, n. 2, p. 129-136, 2009.

VAINSENCHER, S. A. Macambira. Pesquisa Escolar onLine, Fundação Joaquim Nabuco, Recife. 2010. Disponível em: <http://www.fundaj.gov.br>. Acesso em: 18 de fevereiro de 2016. 